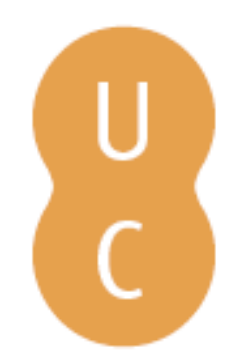

\title{
nommalina
}

\section{Síntese sobre a história da ditadura em Roma}

\author{
Autor(es): $\quad$ Brandão, José Luís \\ Publicado por: Imprensa da Universidade de Coimbra \\ URL \\ persistente: \\ URI:http://hdl.handle.net/10316.2/36921 \\ DOI: \\ DOI:http://dx.doi.org/10.14195/978-989-26-0954-6_11
}

Accessed : $\quad$ 26-Apr-2023 14:00:06

A navegação consulta e descarregamento dos títulos inseridos nas Bibliotecas Digitais UC Digitalis, UC Pombalina e UC Impactum, pressupõem a aceitação plena e sem reservas dos Termos e Condições de Uso destas Bibliotecas Digitais, disponíveis em https://digitalis.uc.pt/pt-pt/termos.

Conforme exposto nos referidos Termos e Condições de Uso, o descarregamento de títulos de acesso restrito requer uma licença válida de autorização devendo o utilizador aceder ao(s) documento(s) a partir de um endereço de IP da instituição detentora da supramencionada licença.

Ao utilizador é apenas permitido o descarregamento para uso pessoal, pelo que o emprego do(s) título(s) descarregado(s) para outro fim, designadamente comercial, carece de autorização do respetivo autor ou editor da obra.

Na medida em que todas as obras da UC Digitalis se encontram protegidas pelo Código do Direito de Autor e Direitos Conexos e demais legislação aplicável, toda a cópia, parcial ou total, deste documento, nos casos em que é legalmente admitida, deverá conter ou fazer-se acompanhar por este aviso. 
JOSÉ LUÍS BRANDÃO FRANCISCO DE OLIVEIRA (COORD.)

IMPRENSA DA

UNIVERSIDADE

DE COIMBRA

COIMBRA

UNIVERSITY

PRESS
HISTÓRIA DE
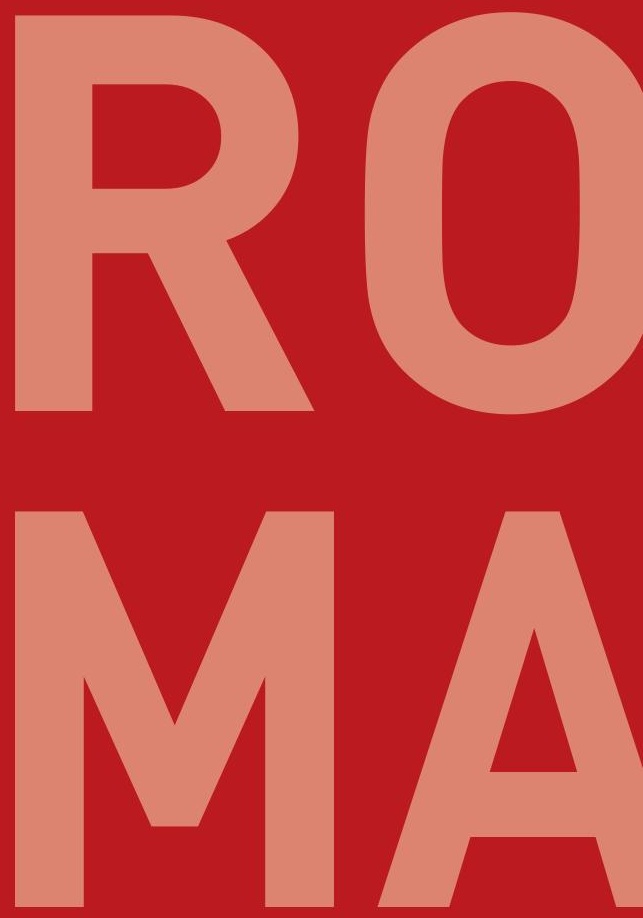

ANTIGA

VOLUME I

DAS ORIGENS À

MORTE DE CÉSAR 


\section{SÍNTESE SOBRE A HISTÓRIA}

\section{DA D ITADURA EM ROMA}

José Luís Brandão

Universidade de Coimbra

Centro de Estudos Clássicos e Humanísticos

Sumário: As teorias sobre a introdução da ditadura em Roma. Possíveis influências externas e/ou fruto de desenvolvimentos constitucionais internos. Funções dos ditadores, a sua frequência ao longo da República. As particularidades das ditaduras de Sula e de César: transformação da magistratura em forma de governo autoritário e progressivamente ilimitado no tempo.

Dada a importância que a ditadura teve no desenlace da República e a influência que alcançou na modernidade justifica-se, para concluir este volume, uma sinopse sobre a evolução desta magistratura, cuja conceção do senso comum atual difere da tradição romana, pelo menos no que se refere ao desempenho anterior a Sula e César. Em Roma, a ditadura apresentava-se como uma magistratura usada em situações especiais, contudo era um cargo legitimado pela "constituição", e que, na essência, não deve ser confundido com a arbitrariedade dos governos despóticos modernos, nem com usurpações ilegais do poder, nem sequer com a representação retórica antiga do tirano helenístico. A sua criação é normalmente colocada no início da República, em concomitância com 
as magistraturas ordinárias, como uma espécie de salvaguarda do Estado para ocasiões de emergência que os magistrados eleitos não poderiam resolver por si. Tratava-se, portanto, de um cargo de nomeação para uma tarefa específica, a realizar num determinado tempo, e tão antigo como a República romana, ou talvez mais.

Para tentarmos compreender a origem, âmbito e evolução do cargo temos de ter em conta o contexto em que a tradição o apresenta, os alvores da República, uma época para nós bastante obscura, cujas instituições são aparentemente objeto de projeção retrospetiva, operada pelos historiadores do final da República, a partir do tempo em que eles viviam. Vimos no capítulo 3 que, em época de crise aguda, podia nomear-se um dictator (ou magister populi), designado geralmente por um dos cônsules, normalmente por seis meses. A principal função do ditador seria o comando militar, como sugere o nome original, magister, que se preserva por toda a República no auxiliar dele, o 'comandante de cavalaria' (magister equitum), mas havia outras missões para a qual podia ser escolhido.

Esta é a formulação oficial de base para o funcionamento daquela magistratura ${ }^{1}$. Mas os diferentes relatos e a comparação das fontes sugerem algo mais complexo e misterioso. No final da Monarquia e no início da República, Roma parece ter sido palco de atuação de uma série de guerreiros, usurpadores e tiranos, o que faz supor que os órgãos da República não funcionaram imediatamente tal qual os conhecemos, mas que houve uma evolução das instituições, incluindo da ditadura.

\section{Controvérsias sobre a origem da ditadura}

Os críticos têm-se dividido, por um lado, entre os que consideram a ditadura uma instituição nascida da República e os que a fazem remontar à época monárquica, e, por outro, entre os que a consideram uma

\footnotetext{
1 Vide Lintott 1999 109-115.
} 
influência das outras cidades latinas (ou mesmo etruscas ${ }^{2}$ ) e os que a consideram uma magistratura tipicamente romana ${ }^{3}$. A origem e evolução da ditadura tem suscitado diversas teorias que, por vezes, a apresentam como um estado intermédio de governo entre os reis e os cônsules (ou inicialmente pretores). Há quem sugira, pois, que, na transição, se poderia ter operado a substituição do rei pelo ditador (magister populi), que por sua vez se fazia acompanhar do mestre de cavalaria (magister equitum $)^{4}$; e, como os dois nomes apareciam emparelhados na lista oficial dos magistrados (os Fasti), poderiam ter sido, depois, interpretados como cônsules pelos historiadores romanos 5 .

Os autores antigos concordam que T. Lárcio foi o primeiro ditador, em datas que variam entre 501 e 497 a.C., e o nome é etrusco, como o de outros magistrados dos primeiros tempos da República. Mas há quem sugira que a nomeação do magister populi (mais tarde chamado dictator) pode já vir mesmo do tempo da Monarquia, sendo nomeado pelo rei ${ }^{6}$. De facto, o ditador aparecia como magistratura anual em outras cidades do Lácio, como Arícia e Lanúvio. Nesta última, o ditador coexistia com um rex sacrorum. O mesmo se passaria em Alba Longa, pois há notícia de que os reis foram substituídos por ditadores anuais antes da conquista romana. Em Roma, poderia ter acontecido algo de paralelo. De resto, vimos (cap. 2) que os eruditos lêem o nome do guerreiro que Cláudio identifica com Sérvio Túlio, Mastarna (Macstarna), como composto de magister, isto é, 'comandante', o que faz pensar num magister populi que, como se disse (cap. 3), poderia ser a designação primitiva do ditador ${ }^{7}$.

\footnotetext{
2 Há quem identifique o ditador com o Zilath etrusco, magistratura entendida como equivalente de pretor ou de governador, mas que não parece sequer ser anual ou ter correspondência com ditadura. Pelo contrário, parece ser mesmo equivalente de rei. Vide Cornell 1995 230-232.

3 Vide Ridley 1979 303-309.

${ }^{4}$ Tese de Beloch e De Martino, apud Cornell 1995228.

5 Vide Alföldi 1963 81; Gagé 1976 88; Mazzarino 1992 183-191.

${ }^{6}$ Vide Broughton 1951 10; Mazzarino 1992 179-184; Cornell 1995 221-223; Lintott 1999 109-113.

7 Vide Cornell 1995 233-235
} 
Vimos também (cap. 3 e 5.1) que, depois do ataque de Porsena, os Romanos se confrontaram com a Liga Latina, que apoiava as pretensões de Tarquínio, conflito que culminou na batalha do Lago Regilo, em 499 ou $496^{8}$, e em que os Romanos, vencedores, impuseram definitivamente a sua supremacia sobre a Liga Latina9. É precisamente no contexto da guerra com a Liga Latina que, segundo Lívio (2.18.3-4), surgiu a ideia de criar o primeiro ditador. Um fragmento das Origens de Catão o Antigo sugere que seria um ditador a presidir à confederação na dedicação do santuário de Arícia ${ }^{10}$. A menos que este fosse um cargo meramente religioso, a necessidade de recorrer esporadicamente em Roma a um magistrado com um imperium igual ao dos dois cônsules pode ter sido inspirada pela forma de liderança da Liga Latina ${ }^{11}$. Todas estas hipóteses sobre as origens da ditadura são verosímeis ou até complementares, mas a falta de uma confirmação definitiva faz com que a questão continue em aberto.

\section{Funções dos ditadores e evolução da magistratura}

Ser ditador era visto pela mentalidade republicana como uma função altruísta e patriótica. A história moralista de Cincinato é apontada como um paradigma da abnegação, austeridade e simplicidade dos heróis dos velhos tempos. Em resumo, enquanto aquele varão andava a lavrar, uma delegação do senado veio comunicar-lhe que tinha sido nomeado dictator para ir combater os Équos. Cincinato pediu a toga à mulher, reuniu um exército, venceu o inimigo, depôs o cargo e voltou para o $\operatorname{arado}^{12}$. A história atesta também o caráter sazonal da atividade militar naquela época de meados do século V a.C. Com o decorrer do tempo, muda a natureza

\footnotetext{
${ }^{8}$ Liv. 2.19-20; D.H. 6.2 ss.

9 Vide Cornell 1995 297-298; Forsythe 2005 147-149.

10 Cat. Or. Fr. 58 P.

11 Sugere Ridley 1979308.

12 Liv. 3.26 ss.
} 
da guerra, do exército e dos seus modelos de comando; aumenta a extensão dos territórios, com repercussões económicas e sociais, e altera-se o poder relativo entre senado, magistraturas e assembleias. Temos de ter em conta que o dinamismo da constituição Romana permitia evoluções e adaptações sancionadas pelo voto popular.

Ao longo da história de Roma foram nomeados numerosos ditadores: estão registados 85 entre 501 e 202 a.C. A verdade é que as ocorrências foram diminuindo, e, depois da segunda Guerra Púnica (218-202 a.C.), este cargo entrou em declínio. Se no século IV, em plena expansão romana através da Itália, temos um ditador nomeado a cada três anos para comandos militares, no século III, já só os temos em emergências causadas no decorrer da primeira e da segunda Guerras Púnicas. A nomeação de ditadores perde então terreno para a prorrogação das magistraturas, gerida pelo senado, de forma a que os comandantes pudessem concluir as campanhas em curso. E, a partir daí, só voltamos a ter um ditador em Sula, já no século I a.C., mas trata-se de uma ditadura de cariz diferente, como veremos. Tal decréscimo parece resultar do facto de a expansão de Roma pelo Mediterrâneo ter reforçado o papel de uma oligarquia senatorial, rica e fortemente competitiva, cujos elementos se controlavam mutuamente e resistiam a colocar o poder de dois na mão de um¹3.

Em todo o caso, embora na sua maior parte fossem nomeados para resolver situações de grande perigo na guerra (rei gerendae causa), as funções dos ditadores não se confinavam às militares. Também podiam ser designados para outras missões específicas, como promover eleições (comitiorum habendorum causa) na ausência dos cônsules, para lidar com distúrbios civis (seditiones sedandae causa), como investigar conspirações na Campânia em 314 a.C. (quaestio extraordinaria), ou para assuntos religiosos, por o seu imperium ser maior que o dos cônsules ${ }^{14}$. Com efeito, o referido fragmento de Catão coloca um dictator da Liga Latina a dedicar o santuário de Diana no bos-

\footnotetext{
13 Vide Cornell 1995 372-373.

${ }^{14} \mathrm{O}$ dictador teria na origem algo de religioso e só assim os Romanos admitiam colocar um tal poder nas mãos de um só homem. Vide Cohen 1957304 ss.
} 
que de Arícia na presença dos povos confederados ${ }^{15}$. Na sequência de uma pestilência, em 363, foi, segundo Lívio (7.2-3), restaurada, para propiciar os deuses, uma prática antiga (lex uetusta) de nomear um ditador para colocar um prego no templo do Capitólio (uma observância que, segundo o historiador, era no início levada a cabo pelo praetor maximus, título inesperado cujo significado tem gerado discussão). Foi então nomeado dictator clavi fingendi causa ('ditador para a fixação do prego') Lúcio Mânlio Capitolino Imperioso, que nomeou seu mestre de cavalaria L. Pinário Nata. Outros ditadores terão sido nomeados para esta função em 331, talvez em 313 e, finalmente, em 263 a.C. ${ }^{16}$ Outros foram criados para promover feriae (dias festivos) para culto religioso: em 344, para afastar um mau presságio, e em 257, para promover as Feriae Latinae em honra de Júpiter Laciar, venerado no Monte Albano. Em 208, no contexto das lutas contra Aníbal na segunda Guerra Púnica, foi nomeado, na ausência dos cônsules (um estava morto e outro ferido), um ditador para celebrar jogos votivos e promover eleições de cônsul e pretor para o ano seguinte. Em 202, foi nomeado um ditador para promover as eleições para 201, mas acabou por ter de dirigir uns jogos votivos em honra de Ceres, uma vez que tempestades impediam a reunião das assembleias de voto ${ }^{17}$.

A ditadura não equivalia em princípio a uma suspensão da constituição. Lívio (2.18.8) e Dionísio de Halicarnasso (6.58.2), entre outros, afirmam que a autoridade do ditador não estava subordinada nem aos cônsules nem ao direito de apelo para o povo (provocatio), mas o próprio Lívio dá exemplos ao longo da sua obra que mostram que não foi sempre assim: pelo menos a partir de meados da República estariam sujeitos ao direito de apelo ${ }^{18}$ e mesmo ao veto dos tribunos da plebe ${ }^{19}$. O ditador possuiria

15 Vide Scullard 196151 e 422; Cornell 1995 297-298.

16 Segundo Cohen 1957 305-308, seria normalmente um cônsul a fixar um prego para contagem dos anos desde o início da República, e só em tempos de calamidade se recorria a um ditador para tal função, numa cerimónia aparentemente diversa da anterior. Mas Lívio parece fazer uma mescla das duas.

17 Para uma síntese dos ditadores nomeados para questões religiosas, vide Kaplan 1973/74 172-175.

18 Cf. Liv. 2.30; 8.33.

19 Cf. Liv. 27.6.5. 
uma espécie de imunidade enquanto desempenhava o cargo, mas podia ser perseguido judicialmente depois de resignar ${ }^{20}$.

\section{Caráter das ditaduras de Sula e de César}

Duas ditaduras se destacaram no final da República: a de Sula e a de César. Estas já não seguiam o modelo anterior; antes se aproximam dos despotismos modernos, fundados em golpes de estado, e da conceção retórica da tirania. De resto, já na antiguidade havia quem não acreditasse na bondade que os romanos creditavam à ditadura, mesmo no que se refere aos primeiros tempos da República. Dionísio de Halicarnasso (5.70-77), que escreve em grego as suas Antiguidades Romanas no final do século I a.C., situa a criação desta magistratura não no contexto da guerra com os Latinos, mas dos conflitos internos entre patrícios e plebeus, como uma forma de reforçar o poder dos primeiros contra as revoltas dos segundos. Por isso, definia a ditadura como uma "tirania eletiva" (5.70) para abolir temporariamente as proteções legais do povo e proteger os interesses dos nobres. Para aquele autor, a ditadura de Sula teve o efeito de dar a perceber aos romanos a verdadeira face tirânica de tal magistratura (5.77), pelo que não considera que foi Sula a distorcer da ditadura e a abusar do poder ${ }^{21}$. Mas parece estar a projetar retroativamente a partir do seu tempo e a simplificar, à luz de uma conceção mais grega, a diversidade de tarefas que requeria uma ditadura.

Com efeito, Sula, depois da morte dos cônsules na guerra civil, convenceu o interrex indigitado pelo senado, L. Valério Flaco, a, em vez de promover eleições, propor uma lei que o nomeasse ditador por um período indeterminado, contrariamente ao costume, e com poderes legislativos (dictator legibus scribendis et Reipublicae constituenda) ${ }^{22}$. A lei foi votada e aprovada nos comitia centuriata, aterrorizados pelos massacres entretanto cometidos. Salvaguardava-se a legalidade, ao menos formalmente.

\footnotetext{
20 Cf. Liv. 9.26. Vide Lintott 1999 111-113.

21 Vide Kalyvas 2007 419-423.

22 Vide atrás Vasco Mantas, cap. 8 \$7.
} 
Para Apiano, outro autor grego (oriundo de Alexandria), mas já do tempo dos Antoninos (séc. II d.C.), o que distinguia Sula dos ditadores anteriores era o facto de estes terem exercido com limitação de tempo; e, uma vez que a ditadura não era mais que uma tirania a prazo, Sula limitar-se-ia a completar a lógica tirânica do cargo ${ }^{23}$. Mas parece que temos aqui dois referentes diversos: por um lado, a lógica da democracia ateniense, que servirá de ponto de partida a Dionísio e Apiano; e, por outro, além de uma visão aristocrática romana, a complexa dinâmica da constituição da República romana, presente em Lívio (e outros escritores de Annales). E os públicos para que escrevem terão a sua importância.

Dionísio de Halicarnasso propõe-se escrever para colmatar a ignorância dos Gregos acerca do passado Romano ${ }^{24}$ e para demonstrar que Roma é, ao fim e ao cabo, uma cidade grega ${ }^{25}$. Da mesma forma, Apiano procura explicar as instituições Romanas à sua audiência grega oriental. É portanto natural que tanto um como outro use como chave de leitura conceitos e mundividências gregos que pudessem ser facilmente apreensíveis pelos seus públicos, mas que facultam uma leitura filtrada.

$\mathrm{Na}$ política interna entrou entretanto em jogo outro fator: o exército. As reformas que Mário operou em finais do século II a.C., de modo a responder à crescente necessidade de efetivos, levaram à criação de um exército profissional em que os soldados dependiam do seu general para a partilha dos despojos e sobretudo distribuição de terras na altura de serem licenciados, o que potenciou o recurso aos soldados e aos veteranos nas lutas civis. A ditadura de Sula é, de facto, nova também na forma. Era uma ditadura militar que resultava da vitória na guerra civil sobre os partidários de Mário e assentava no apoio do exército. O aspecto mais

23 Cf. App. BC 1.3 e 99. Vide Kalyvas 2007 423-428. Segundo este autor, Dionísio e Apiano têm o mérito de propor a redefinição daquela magistratura romana como uma ditadura legal - ao invés da conceção patriótica presente em Lívio - e a unificação dos dois tipos de ditadura através da continuidade histórica e da coerência constitucional. Mas Kalyvas parece ter valorizado demasiado a síntese daqueles autores gregos, uma visão externa, em detrimento da tradição romana.

${ }^{24}$ D.H. 1.4.2.

25 D.H. 1.5. 
negro foram as proscrições, que serviram inclusive para enriquecer os apoiantes do ditador mediante a eliminação de adversários ricos.

O programa legislativo de Sula teve o propósito e o efeito de reforçar o poder do senado e enfraquecer o poder dos tribunos da plebe, que desde os Gracos se tinha revelado uma poderosa arma nas mãos das diversas facções aristocráticas e um trampolim para promover fulgurantes carreiras políticas. Por isso, esta ditadura era, no fim de contas, um produto da sua época: as lutas civis que deflagraram em finais do século II, que ele tentava resolver de um modo conservador e tradicionalista 26. De qualquer modo, Sula não quereria uma ditadura para toda a vida e, ao fim de algum tempo (em 79 a.C.), abdicou do cargo.

A verdade é que o perigo de o ditador abusar do poder passava a estar latente. Em 52 a.C., o senado nomeia Pompeio cônsul único para evitar torná-lo ditador. César, como Sula, inaugura uma ditadura estabelecida sobre o poder militar, e enquanto Sula se apoiava no "partido" aristocrata (optimates), César apoiava-se nos populares. Tanto um como outro usaram como justificação para os seus atos o abuso do poder da parte contrária, apoiando-se na força dos respectivos exércitos. Depois da conquista da Gália, César, como vimos no capítulo 10, contava com um exército experimentado na guerra e devotado ao seu comandante, de quem esperava as devidas recompensas, e disposto a segui-lo para além do Rubicão, apesar da importante deserção de Labieno.

Perante a fuga de Pompeio para a Grécia com os principais magistrados, uma vez que, na ausência dos cônsules, só um ditador podia convocar as eleições para 48, César fez-se nomear ditador (comitiorum habendorum causa) através de uma lei (lex de dictator creando) proposta por um pretor ${ }^{27}$. A partir daqui vai entremeando ditadura e consulados. Ao fim de 11 dias, cumprida a tarefa e eleito cônsul, abdicou da ditadura e dirigiu-se para Brundísio, no encalço de Pompeio. Em 48 a.C., na ausência de César, o cônsul Servílio nomeou-o ditador por um ano,

\footnotetext{
26 Vide Hurlet 1993 169-172.

27 Havia precedentes na história romana: a nomeação de Fábio Máximo em 217 a.C., depois do desastre do lago Trasimeno, e de Q. Fúlvio Flaco, para promover eleições na ausência dos cônsules em 210. Cf. Liv. 22.31.8; 27.5.16. Vide Hurlet 1993 37-39.
} 
provavelmente para escrever as leis e reorganizar o Estado (legibus scribundis et rei publicae constituendae), com António como comandante de cavalaria (magister equitum). Em 47 a.C., César renuncia à ditadura e torna-se cônsul para o ano seguinte, escolhendo como colega Marco Lépido. Em 46, foi nomeado ditador por um período de dez anos (com Lépido como comandante de cavalaria), contrariamente ao costume, e em Fevereiro de 44, nomeiam-no ditador para toda a vida (dictator perpetuus), ao mesmo tempo que detém o consulado desse ano juntamente com M. António. Assim a ditadura de César se torna num instrumento para efetuar o progressivo propósito monárquico do seu poder ${ }^{28}$. Passado pouco tempo, nos idos de Março, César foi apunhalado até à morte no início de uma sessão do senado.

Depois do cesaricídio, M. António, cônsul em exercício e senhor da situação na crise que se gerou, terá abolido a ditadura ${ }^{29}$; mudança interessante, uma vez que tinha abusado do cargo quando era comandante de cavalaria. Duas décadas mais tarde, em 22 a.C., é o próprio senado e o povo a tentar oferecê-la por duas vezes a Augusto $^{30}$, que a recusa para alardear a legalidade do novo regime ${ }^{31}$. A ditadura tinha-se tornado em algo que se aproximava da aspiração ao reinado, ambição intolerável para um romano e habilmente rejeitada pela ideologia do principado augustano.

Em suma, a ditadura em Roma entende-se à luz da lógica da constituição romana e do seu desenvolvimento. Aparece numa posição de equilíbrio entre o tabu em relação à Monarquia e a necessidade que por vezes o Estado tinha de ter um líder forte e único, com um imperium reforçado por questões de conflitos, externos ou internos, ou para aplacar os deuses. No final da República, o equilíbrio quebrou-se e a instituição acabou usada nas lutas entre facções. De missão entregue pelos cônsules, passou a ser

28 Vide Hurlet 1993 172-175.

29 Cf. Cic. Phil. 1.3.

30 Cf. Aug. RG 5.

31 Segundo Suetónio (Aug. 52), Augusto, num ato teatral, caiu de joelhos e com o peito desnudo, a suplicar ao povo que lhe não oferecesse a ditadura. 
uma forma de governo, cada vez mais longa. Utilizada para tentar sanar os males de que sofria a República, acabou por ser um dos fatores que levou ao seu fim e à criação do principado, uma nova forma de monarquia que tornava em ficção a constituição republicana.

\section{Tábua Cronológica}

Entre 501 e 497 - Nomeação do $1^{\circ}$ ditador, T. Lárcio

499 ou 496 - Batalha do Lago Regilo

363 - Restauração da prática antiga de nomear um ditador para colocar um prego no templo do Capitólio

82/81 -Sula nomeado dictator legibus scribendis et Reipublicae constituenda

79 - Sula abdica da ditadura

49 - César ditador para promover eleições para 48: comitiorum habendorum causa

48 - César ditador por um ano

46 - César nomeado ditador por um período de dez anos

44 (fev.) - César dictator perpetuus

- (15 mar.) - Cesaricídio

\section{Bibliografia}

Alföldi, A. (1971), Early Rome and the Latins. Ann Arbor, University of Michigan Press.

Broughton, T. R. \& Patterson, M. (1951), The Magistrates of the Roman Republiic I. New York.

Canfora, L. (52000), Giulio Cesare. Il dittatore democrático. Bari, Laterza.

Cohen, D. (1957), "The Origin of Roman Dictatorship", Mnemosyne $4^{\text {th }}$ series 10 300-318.

Cornell, T. J. (1995), The beginnings of Rome. London, Routledge.

Forsythe, G. (2005), A critical history of early Rome. Berkeley/London, University California Press.

Gagé, J. (1976), La chute des Tarquins e les débuts de la Républic. Paris.

Giovannini, A. (1993) "Il passagio dalle istituzioni monarchiche alle istituzioni republicane", in Convegno sul tema "Bilancio critico su Roma arcaica fra Monarchia e Republica". Atti dei Convegni Lincei 100. Roma, Academia dei Lincei, 75-96.

Hurlet, F. (1993), La dictature de Sylla: monarquie ou magistrature republicaine? Essai d'histoire constitutionelle. Bruxelles/Rome, Institut Historique Belge de Rome.

Kaplan, A. (1973-74), "Religious dictators of the Roman Republic", CW 67 172-175.

Kalivas, A. (2007), "The Tyranny of Dictatorship: when the Greek Tyrant met the Roman Dictator", Political Theory 35 412-442. 
Lintott, A. 1999, The Constitution of the Roman Republic. Oxford, University Press.

Mazzarino, S. (1992), Dalla monarchia allo stato republicano. Milano, Rizzoli.

Ogilvie, R. M. (1976), Early Rome and the etruscans. Hassocks, The Harvester Press.

Ridley, R. T. (1979), "The origin of the Roman dictatorship: an overlooked opinion", $R h M$ 122 303-309.

Scullard, H. H. (51982), From the Gracchi to Nero. London, Routledge.

Shorter, D. (22005), The fall of the Roman Republic. London-New York, Routledge. 